\title{
BMJ Open Industrially produced trans fat in popular foods in 15 countries of the former Soviet Union from 2015 to 2016: a market basket investigation
}

\author{
Steen Stender
}

To cite: Stender S. Industrially produced trans fat in popular foods in 15 countries of the former Soviet Union from 2015 to 2016: a market basket investigation. BMJ Open 2019;9:e023184. doi:10.1136/ bmjopen-2018-023184

- Prepublication history and additional material for this paper are available online. To view these files, please visit the journal online (http://dx.doi. org/10.1136/bmjopen-2018023184).

Received 25 March 2018 Revised 12 December 2018 Accepted 12 December 2018

Check for updates

(c) Author(s) (or their employer(s)) 2019. Re-use permitted under CC BY-NC. No commercial re-use. See rights and permissions. Published by BMJ.

Department of Nutrition, Exercise and Sports, University of Copenhagen, Frederiksberg, Denmark

Correspondence to Professor Steen Stender; stender@nexs.ku.dk

\section{ABSTRACT}

Objective To minimise the intake of industrially produced trans fat (I-TF) and decrease the risk of coronary heart disease, several countries have implemented a legislative restriction on I-TF in foods. The objective of this study was to investigate the presence of I-TF in biscuits/cakes/wafers in 15 countries of the former Soviet Union that all have a high coronary mortality rate compared with countries in Western Europe.

Methods Three large supermarkets in 15 capitals were visited in 2015 or 2016. Prepackaged biscuits/cakes/ wafers were bought if the list of ingredients disclosed that the product contained more than $15 \mathrm{~g}$ of fat per 100 $\mathrm{g}$ of product and if partially hydrogenated fat or a similar term, including margarine, refined fat or confectionery fat, were mentioned. Samples of the foods were subsequently analysed for total fat and TF.

Results Some 994 products contained more than 2\% total fat as I-TF (illegal in Denmark). In Armenia, 91 different products had a mean value (SD) of $21(11) \%$ fat as I-TF. In Estonia, there were eight products with $14(10) \%$ fat as I-TF. The other 13 countries had values between those of Armenia and Estonia. In several countries, a major portion of the products was imported from Russia and Ukraine. The mean shelf life (SD) of 673 packages was 218 (75) days. The \% TF in the fat of the products produced in Russia and in Ukraine in relation to the date of production both declined by approximately $10 \%$ points during the 2 -year collection period. Conclusions The findings suggest that I-TF is used in popular foods in all 15 countries of the former Soviet Union. Therefore, these findings indicate a possible way for some reduction of the high coronary mortality rate in these countries.

\section{INTRODUCTION}

High amounts of trans fat (TF) in food, that is, more than $5 \% \mathrm{TF}$ in total fat, originate from the industrial hydrogenation of edible oils. Compared with non-hydrogenated oils, fats containing industrially produced trans fat (I-TF) are solid at room temperature, have some technical advantages for food processing and prolong the shelf life of products. TF are not synthesised in the human

\section{Strengths and limitations of this study}

- A strength of this study is that the presence of industrially produced trans fat in popular foods was systematically investigated for the first time in each of the 15 countries of the former Soviet Union that all have a high coronary mortality rate and a population of nearly 300 million people.

- A limitation of the study is that only prepackaged biscuits/cakes/wafers were investigated for trans fat, and no other food groups, such as shortenings and margarines, and no unpackaged foods, such as baked goods, sweet rolls, pastries, buns and even unpackaged biscuits/cakes/wafers, were investigated.

- A limitation is the assumption that if certain words were not present in the list of ingredients, the product contained less than $2 \%$ total fat as trans fat.

- Another limitation is that the average daily intake of trans fat was not measured in any of the subgroups of the populations but instead was inferred from the availability of popular foods with high amounts of trans fat in large supermarkets.

body and are not required in the diet but are absorbed and metabolised. I-TF can be found at varying concentrations in biscuits, pastries, margarine, spreads, confectionery creams and fillings and fried foods such as potato crisps. Fat from ruminants, for instance, in dairy products, contains up to $5 \% \mathrm{TF}$ ( $\mathrm{R}-\mathrm{TF}$ ), which is considerably lower than the up to $50 \% \mathrm{TF}$ that may be present in partially hydrogenated fat in human food. In a double-blind, randomised controlled trial in humans, R-TF and I-TF resulted in the same increase in low-density lipoprotein (LDL) cholesterol in blood when the two different types of fat were provided in the diet at the same amount. ${ }^{1}$ This result suggests that R-TF and I-TF have similar harmful effects on plasma lipoproteins.

Observational studies suggest that there is an association between the dietary intake of 
I-TF and increased risk of coronary heart disease (CHD). ${ }^{2}$ The association is further corroborated by an association between plasma TF levels and CHD. ${ }^{3}$ Plausible mechanisms for the association involving an increase in plasma LDL cholesterol ${ }^{4}$ and unfavourable 'beyond lipid effects' on inflammatory cells that are important for atherogenesis $^{5}$ suggest a causal relationship, even with the absence of randomised studies with hard clinical endpoints. ${ }^{6}$ Based on the available evidence, Denmark in 2004 and some counties in New York, USA, in 2007, legally restricted the use of I-TF in the diet. After the restrictions in Denmark, there was a $4.3 \%$ lower yearly mortality rate due to CHD beyond temporal trends. ${ }^{7}$ A similar decline of $4.5 \%$ in the CHD mortality rate was found in the counties with restrictions in New York compared with that in similar counties without restrictions. ${ }^{8}$ Three and more years after the restrictions were enacted in the counties, the combined hospital admission rate for myocardial infarction and stroke events was $6.2 \%$ lower than that in similar counties without restrictions. ${ }^{9}$ These findings from two different groups of researchers strongly suggest that I-TF in the diet promotes CHD and that a restriction in its use reduces CHD. What remains to be explored is to what extent I-TF is still used in popular foods in countries with high rates of CHD mortality.

The 15 countries of the former Soviet Union all have an extraordinarily high rate of CHD mortality compared with that of countries in Western Europe ${ }^{10}$ (online supplementary table A). In a systematic analysis, including 266 country-specific nutrition surveys, the average consumption of TF in 2010 in Central Asia and Eastern Europe, which together include the 15 countries of the former Soviet Union, for adults more than 20 years old, was $0.9 \%$ of total energy intake. ${ }^{11}$ This intake corresponds to approximately $2.5 \mathrm{~g}$ of TF per day per adult and is less than the $1 \%$ of the total energy recommended by WHO. The consumption level was found to be stable since 1990. Among the 21 different regions in the world, Central Asia and Eastern Europe were placed at numbers 5 and 8, respectively, for the lowest average consumption of TF, suggesting that the intake of TF is a minor health problem in these countries. However, the investigators mention the relatively limited availability of data on TF consumption in most of these nations compared with the availability of data on other major dietary factors. ${ }^{11}$ Furthermore, a low average intake of TF in a nation does not exclude a high intake of TF in subgroups of the population if popular foods contain high amounts of I-TF.

Some recent Russian studies, with an abstract in English, mentioned the harmful effect of dietary I-TF on health and pledged to remove I-TF from margarine 'to preserve the health of Russia's population'. ${ }^{12} 13$ A study from Estonia reported on high I-TF in blended spreads, margarines and shortenings that were bought in the Estonian retail markets in 2011. ${ }^{14}$ Additionally, technical reports from WHO have found several types of street foods with high amounts of TF in Dushanbe, Tajikistan in April/May 2016 and in Bishkek, Kyrgyzstan in June/July
$2016 .^{15}$ In a recent systematic review of TF intake and its dietary sources in general populations worldwide based on data from 29 different countries and a demonstration of a substantial reduction in I-TF in many countries, none of the countries of the former Soviet Union were included for either the intake of the general population or for the secondary research question of the study about the composition of fat in biscuits because of the lack of data. ${ }^{16}$ Apparently, there is a pronounced scarcity of newer internationally published data on I-TF in foods in most of these countries. The purpose of the present study was to investigate the presence of I-TF in popular foods in the 15 countries of the former Soviet Union via a newly developed market basket method. ${ }^{17}$

\section{METHODS}

\section{Purchase of biscuits/cakes/wafers in supermarkets}

By using Wikipedia and local tourist information offices, three large supermarkets, preferably chain supermarkets with many large shops across the country, were identified in each capital. ${ }^{18}$ Prepackaged biscuits/cakes/wafers were chosen as the food to be investigated for TF in this study because these types of foods are frequently consumed, easily accessible and transportable at ambient temperature. Furthermore, these foods traditionally contain I-TFrich partially hydrogenated vegetable oils as their major lipid ingredient, and I-TF has previously been found in these foods in high concentrations in some countries in Eastern Europe. ${ }^{19-21}$ The packages of biscuits/cakes/ wafers were obtained in each supermarket by systematically examining the labels of the products. Packages were purchased if their list of ingredients met the following criteria:

- The total fat content was equal to or exceeded $15 \mathrm{~g}$ per $100 \mathrm{~g}$ of product.

- One or more of the following terms was listed: partially hydrogenated fat, hydrogenated fat, hardened fat, refined fat, confectionery fat, deodorised fat, all-purpose fat or margarine.

- If the list of ingredients indicated trans fat $>0 \mathrm{~g}$, these foods were also included.

- Packages with the term 'unhydrogenated fat,' 'fully hydrogenated fat' or 'no trans fat' were not purchased.

If the same package with the same barcode number was found in more than one of the three different supermarkets in the same capital, only the package with the most recent production date was included in the study. Each package was subsequently labelled with an ID number, and duplicate samples of approximately $50 \mathrm{~g}$ each of the product were taken for analysis. The barcode number, the name of the producer, the country of origin and, if available, the best-before date as well as the production date were recorded, and the empty packages were stored. The first two digits (sometimes three digits) of the barcode number were used to identify the country or economic region numbering authority that assigned the manufacturer code. The Russian Federation uses the 
code 46; Ukraine, 482. The manufacturer code is the next five digits, followed by the product code, consisting of five digits. The last digit is the check digit. ${ }^{22}$

To investigate to what extent the presence of biscuits/ cakes/wafers in the capital differed from other parts of the country, biscuits/cakes/wafers were obtained from three different supermarkets in two different regions of the two largest countries Uzbekistan and Russia: in Uzbekistan also in the second largest city Samarkand $(0.4$ million inhabitants and approximately $300 \mathrm{~km}$ from Taskent) and in Russia also in St. Petersburg (5.2 million inhabitants and approximately $800 \mathrm{~km}$ from Moscow). The third largest country was Ukraine. In its capital Kiev, three other large supermarkets were visited (Kiev-2) in addition to the first three that were visited (Kiev-1).

\section{Analysis of TF}

The samples from the various countries were analysed successively in the order they were obtained. The samples that were obtained from the first countries that were visited (Moldova, Belarus, Georgia, Armenia and Kyrgyzstan) were all analysed for TF. In the other countries that were visited later, some packages were obtained with the same barcode number, the same visual appearance and list of ingredients as those on packages where the samples had already been analysed. A sample from the newly found package was analysed only if the best-before date on that package exceeded the best-before date by more than 12 months on a package that already had been analysed. Otherwise, the TF values were carried forward to the new package (online supplementary table $\mathrm{B}$ ).

For analysis, the foods were homogenised, and the fatty acid content was analysed using gas chromatography on a $60 \mathrm{~m}$ highly polar capillary column via a modification of the Association of Official Analytical Chemists (AOAC) 996.06 method. Two procedures were modified in minor ways. In the AOAC 996.06 method, the final step of the extraction/methylation called for $1 \mathrm{~mL}$ of hexane to be added. In the modified method, $4 \mathrm{~mL}$ was added. The $4 \mathrm{~mL}$ of hexane makes it possible to achieve the detection limit needed for low-fat samples. It provides extra volume for subsequent dilutions for high-fat samples in order to achieve results that fall within the range of the detector. The extra volume also provides additional extract for further dilutions and subsequent analysis to optimise separation of cis/trans isomers or if more resolution is needed between other fatty acids. In addition, in the modified method, C11:0 triundecanoin was used as an internal standard. This method makes it possible to obtain total fat as triglycerides, which are then broken down into monosaturated, polysaturated, saturated and total TF. Total TF may consist of up to eight different trans fatty acids. Microbac Laboratories in Warrendale, Pennsylvania, USA conducted all analytical work on the samples. The laboratory underwent annual proficiency testing and was audited every other year to ensure compliance of this method with ISO 17025.
From the peaks in the chromatogram, TF was calculated as a fraction (per cent) of total fat in the product. This value is primarily of interest for food producers, food chemists and food legislators. The total amount of fat in $100 \mathrm{~g}$ of the product was determined from the chromatogram. When that value was multiplied by the TF fraction, the amount of TF in grams per $100 \mathrm{~g}$ of the product was calculated. This value is primarily of interest for the customers and for investigators studying the health effect of intake of TF.

The measurement does not distinguish I-TF from R-TF. If butter as a ruminant fat has been used in the product in addition to partially hydrogenated vegetable oil, some of the TF in the product may be derived from butter that on average contains a few per cent and a maximum $5 \%$ fat as R-TF. In this paper, the term I-TF is used even though a minor portion in certain products may be TF derived from ruminant fat. If butter is present in a product that was analysed for TF in the present study and the value was higher than 5\% TF of total fat, butter diluted the I-TF in the product because butter adds more non-TF than it adds TF. Values larger than 5\% TF in the product are consequently the minimum values for I-TF as a percentage of total fat. In products that contain butter with less than 5\% TF as a percentage of total fat, the I-TF will be lower than the TF value. Such products are less important for the health of the consumer than products with much higher TF values and of less interest for health authorities and food scientists because of their low amounts of TF per 100 $\mathrm{g}$ of product.

\section{Patient and public involvement}

Patients and the public were not involved in the present study.

\section{Statistical analysis}

For each country, simple linear regression models were used to describe the change in $\% \mathrm{TF}$ of total fat as a function of shelf life and over time recorded as a function of the date of production. The statistical software $\mathrm{R}$ was used (R Core Team 2017).

\section{RESULTS}

The number of different packages obtained in three different supermarkets in each of the 15 capitals totalled 1332. Samples from 1068 packages were analysed, and the TF values for each of the remaining 264 packages were taken from a similar package with an identical barcode but obtained earlier in another country and already analysed. Some 994 samples had more than $2 \%$ fat as TF. The different products in each country were ranked according to the I-TF level, which was expressed as grams per $100 \mathrm{~g}$ of the product (figure 1). This latter value tells how much TF the consumer receives when $100 \mathrm{~g}$ of the product is consumed. Each horizontal bar in each panel represents a product with more than $2 \%$ fat as TF. The number of these products is shown together with the 

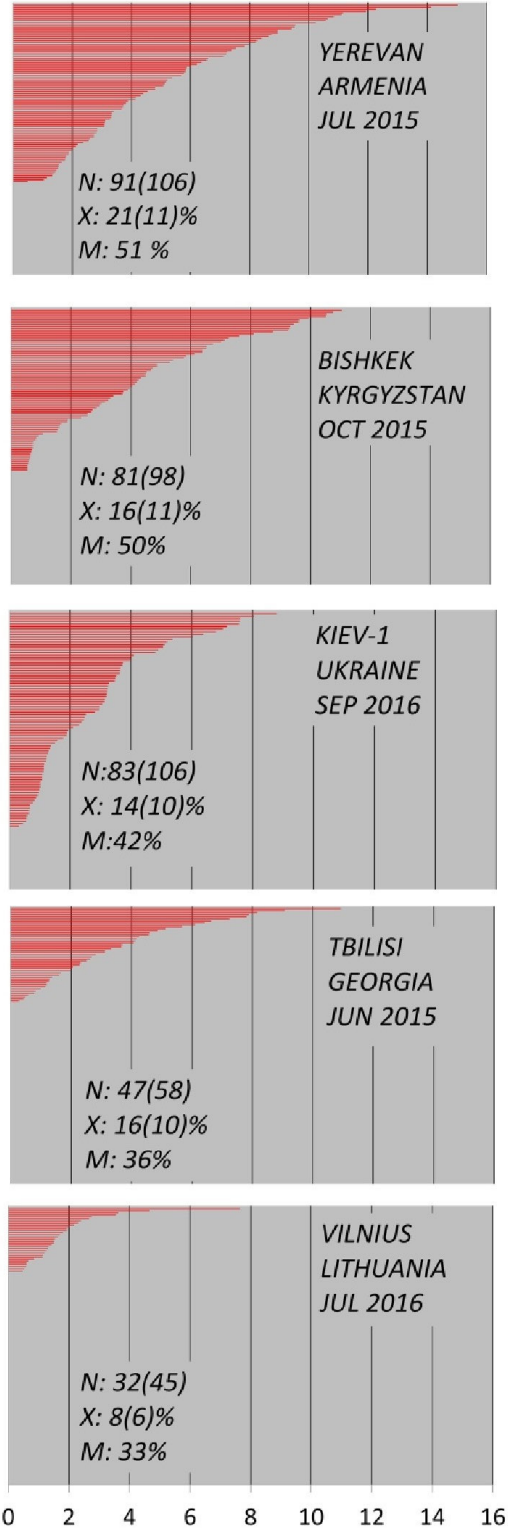
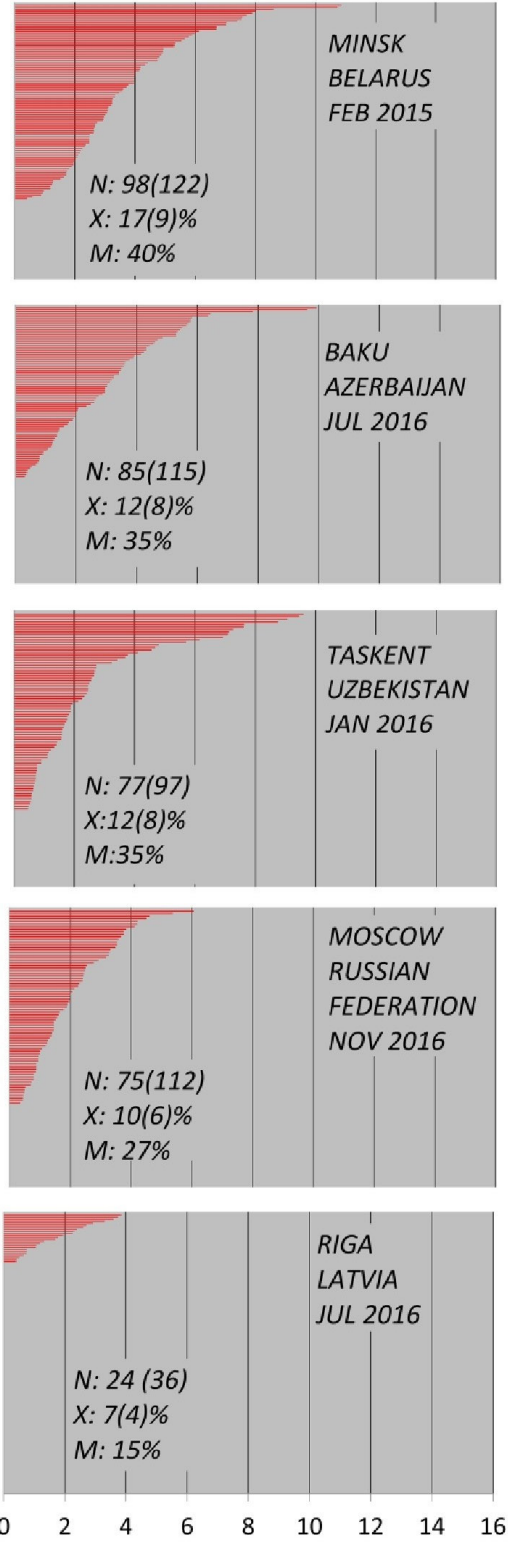
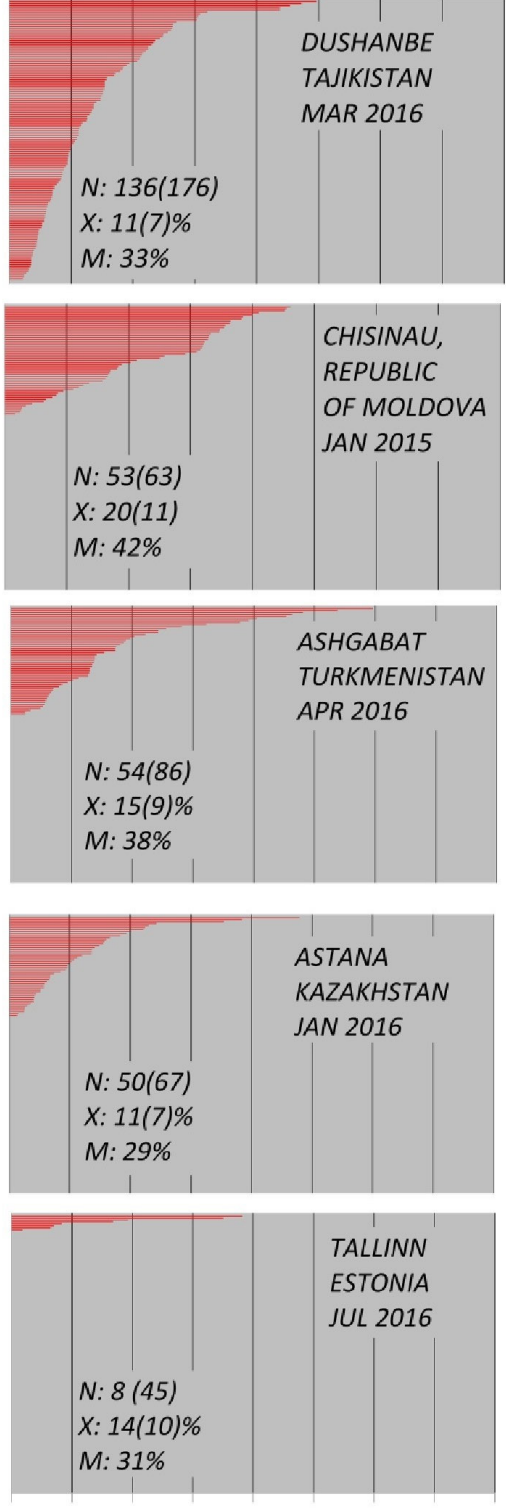

$\begin{array}{lllllllll}0 & 2 & 4 & 6 & 8 & 10 & 12 & 14 & 16\end{array}$

Gram trans fat per 100 gram of product

Figure 1 Amounts of industrially produced trans fat (I-TF) in $100 \mathrm{~g}$ of prepackaged biscuits/cakes/wafers purchased from 2015 to 2016 in three supermarkets in each of the 15 capitals. Each bar in a panel represents a unique product that was bought in that capital. $\mathrm{N}$ is the number of different products with more than $2 \% \mathrm{TF}$ in the total fat content. $(\mathrm{N})$ is the number of packages that met the inclusion criteria. $X$ is the mean value and the SD of the percentages of I-TF in the total fat of the $N$ products, M is the maximal value of I-TF as a percentage of total fat. Each bar in all 15 panels has the same thickness, which means that the area of the bars is comparable between the different panels.

number of packages, given in parentheses that met the inclusion criteria. The products depicted in each panel are all different, but the same product may appear in the panel for two or more countries. The mean values of the percentages of fat that were I-TF in the collection of different products from each of the countries, together with the SD and maximum values, are shown. These percentages are of interest for food producers and for food authorities because they describe the fat that has been used in the food. In some products obtained in Armenia and in Kyrgyzstan, approximately $50 \%$ of the fat was I-TF (figure 1).
In the second largest city, Samarkand, in Uzbekistan, based on the barcode number, $29 \%$ of the packages were similar to the packages found in the capital, Taskent. In St. Petersburg, Russia, $30 \%$ of the products were similar to the products found in Moscow. In Kiev-2, which was the second collection region, $48 \%$ were similar to the packages found in the first collection region, Kiev-1. Even though most of the products were different in the two different regions of the same country, the panels that reflect the availability of biscuits/cakes/wafers with more than $2 \% \mathrm{TF}$ in fat are rather similar (figure 2). This result suggests that the panels presented for each country 

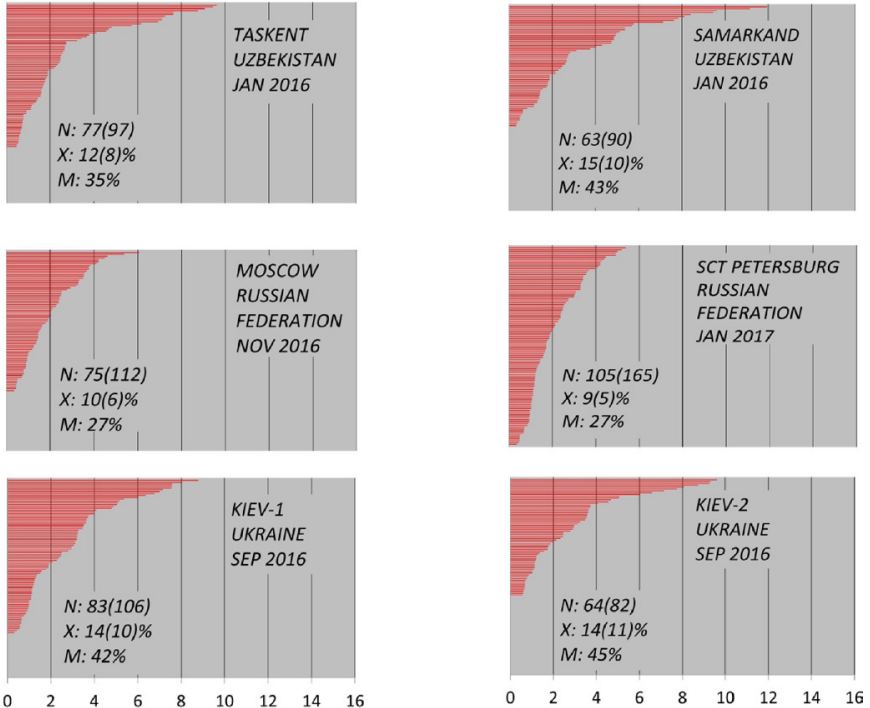

Gram trans fat per 100 gram of product

Figure 2 Legend for this figure is similar to the legend for figure 1. The four upper panels show the results for two of the capitals and for two other large cities in the same country. The lowest two panels show the results from purchases from three large supermarkets in Kiev (Kiev-1) and from three other large supermarkets in the same city (Kiev-2).

in figure 1 represent a pattern found elsewhere in the country and not only in the capital.

For the 994 products with more than $2 \%$ fat as I-TF and that were obtained in the 15 capitals of the former Soviet Union, $52 \%$ were produced in Russia, $26 \%$ in Ukraine, $13 \%$ in own country and $8 \%$ in some other countries, such as Poland and Bulgaria (table 1). For the products produced in Russia, $85 \%$ were obtained outside of Russia and in the other countries of the former Soviet Union combined, not including Ukraine and Lithuania. For the products produced in Ukraine, $69 \%$ were obtained outside of Ukraine in the other countries, excluding Russia. The import patterns of prepackaged biscuits/ cakes/wafers that differed from country to country were exemplified by the patterns observed in Uzbekistan and Kazakhstan (figure 3). The concentrations in grams of TF per $100 \mathrm{~g}$ of product are shown in a panel for each of the two countries, and each product is placed together with other products from the same country of origin. The numbers and the mean values of the concentrations of TF in the fat of prepackaged biscuits/cakes/wafers produced in Russia and in Ukraine but obtained in the various countries of the former Soviet Union are shown in table 1. All of the 75 different products with more than 2\% fat as TF obtained in Moscow were produced in Russia, and 81 of the 83 different products obtained in Kiev-1 were produced in Ukraine. The same pattern was observed in St. Petersburg, Russia and Kiev-2, Ukraine. In each of the countries, except for the three Baltic countries and Belarus, a majority of the products were imported from Russia and Ukraine.
The analysis of shelf life was only conducted for packages produced in Russia and Ukraine, as they were the main exporters to most of the other countries, and in many of the products, especially from Russia, the length of the shelf life in months or days appeared on the package together with the date of production. This is in contrast to prepackaged biscuits/cakes/wafers produced in most countries in the more western part of Europe. These packages only have the best-before date, and the shelf life of the product is usually hidden from the final customer. Products with less than 2\% TF in the fat had shelf lives of approximately 200 days, which is comparable with that of products with a much higher concentration of TF (table 2). The most frequent length of shelf life was 6 months, whether the products were produced in Russia or in Ukraine. The slope of the regression line between shelf life and \% TF of total fat was significantly negative for Ukraine $(\mathrm{p}<0.0001)$ and significantly positive for Russia $(p<0.0001)$. Taken together, the data did not support the conclusion that the higher the concentration of TF in the product, the longer was the shelf life.

Since the samples of biscuits/cakes/wafers were collected between January 2015 and January 2017 and many were produced in Russia and in Ukraine, the \% TF of total fat in the product was depicted in relation to the date of production. The TF concentrations decreased significantly during the 2 years in Russia $(\mathrm{p}<0.0001)$ as well as in Ukraine $(p<0.0001)$, but the decrease did not differ significantly between the two countries $(p=0.12)$ (figure 4). The products from Ukraine had a higher \% TF at the start of the period than the products from Russia. Based on the slopes of the regression lines in figure 4 , the decline for the products from Ukraine was $12.4 \%$ points and for products from Russia $8.4 \%$ points during the 2-year period.

\section{DISCUSSION}

\section{Principal findings}

The findings of this study clearly demonstrate that from 2015 to 2016, I-TF was present in high concentrations, that is, more than $5 \%$ I-TF in the total fat, in many different brands of biscuits/cakes/wafers in the countries of the former Soviet Union, except for the three Baltic countries. This information was not previously available and may be of relevance because of the high coronary mortality rate in these countries. In three of the countries, Russia, Ukraine and Belarus, by far most of the products were produced in the country itself. For the other countries, except for the three Baltic countries, the imports from food producers in Russia and Ukraine made up a major portion of their products with high amounts of TF.

In all of the shops, there were more packages containing biscuits/cakes/wafers that did not have the inclusion terms on the label than packages that had one or more of the terms on the label. This result suggests that there are plenty of biscuits/cakes/wafers without I-TF available in all of the 45 supermarkets. Of the 1332 packages that met 


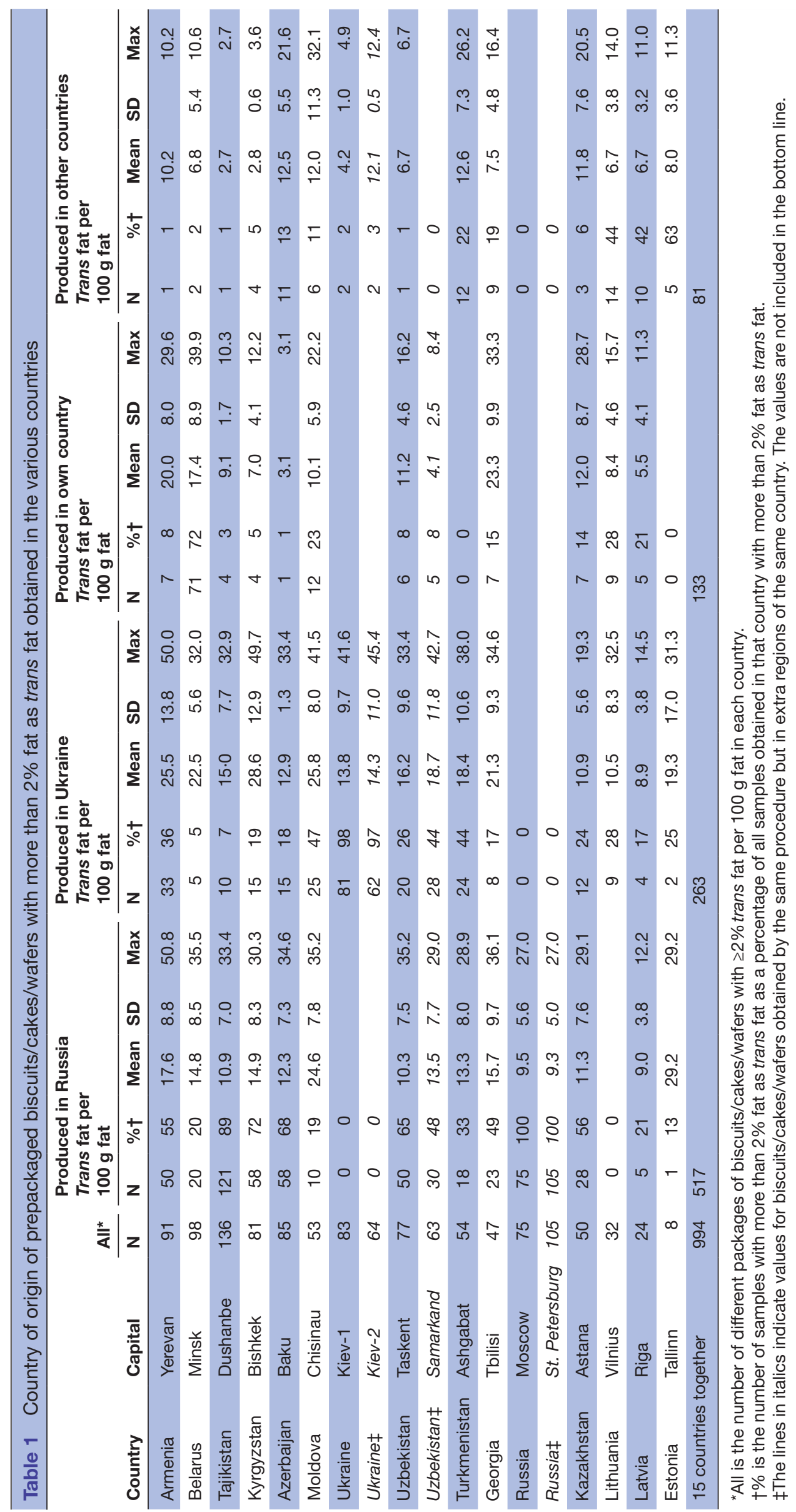


TASKENT, UZBEKISTAN

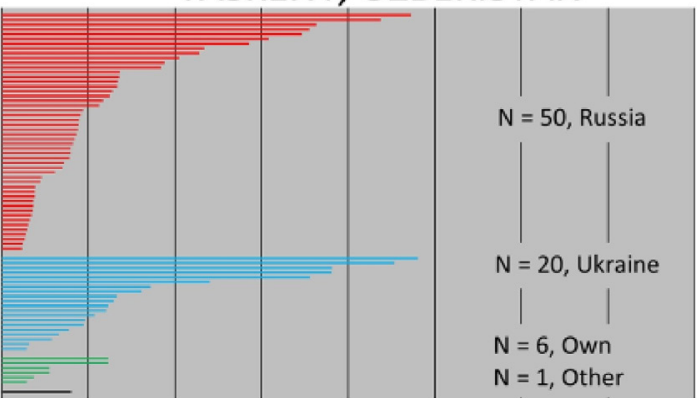

ASTANA, KAZAKHSTAN

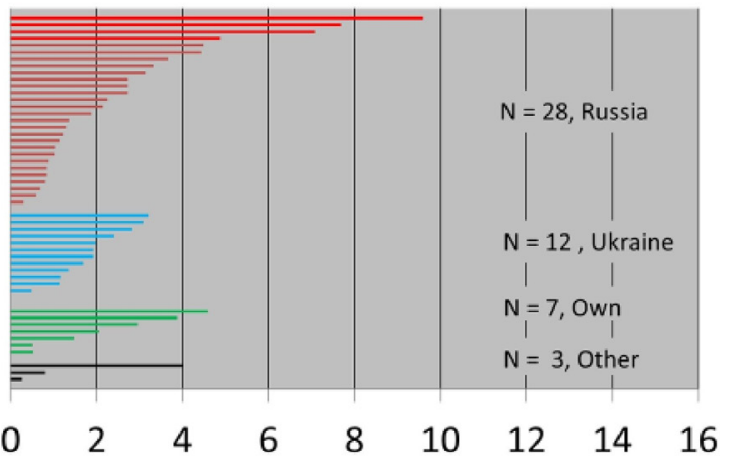

Gram trans fat per 100 gram of product

Figure 3 Amounts of industrially produced trans fat in $100 \mathrm{~g}$ of prepackaged biscuits/cakes/wafers that were obtained in Uzbekistan and in Kazakhstan, with each product in the panel placed together with other products from the same country of origin.

the inclusion criteria and were bought, 335 (25\%) of the products had less than $2 \%$ fat as TF. This result suggests that the inclusion criteria are rather broad in relation to the presence of $\mathrm{TF}$ and/or that the terms on the list of ingredients do not always reflect the composition of the fat in the product. If the list of ingredients did not have the inclusion words, the product may still have had high amounts of TF but were not bought and analysed for TF.

The amount of TF per $100 \mathrm{~g}$ of product that was bought in Moscow did not exceed $6 \mathrm{~g}$ (figure 1), whereas several products that were produced in Russia but obtained in the other countries, such as Uzbekistan and Kazakhstan,

Table 2 Shelf life of prepackaged biscuits/cakes/wafers produced in Russia and Ukraine

\begin{tabular}{lllll}
\hline & \multicolumn{2}{l}{ Produced in Russia } & \multicolumn{2}{l}{ Produced in Ukraine } \\
\hline Trans fat as \% of fat & $<2 \%$ & $\geq 2 \%$ & $<2 \%$ & $\geq 2 \%$ \\
No of samples & 140 & 453 & 24 & 220 \\
Shelf life in days & & & & \\
$\quad$ Mean (SD) & $202(83)$ & $219(70)$ & $286(94)$ & $215(85)$ \\
Range & $59-547$ & $46-396$ & $123-366$ & $46-546$ \\
\hline
\end{tabular}

*Samples obtained in Samarkand, St. Petersburg and Kiev-2 were included if these samples had their own trans fat analysis and a readable shelf life on the package.
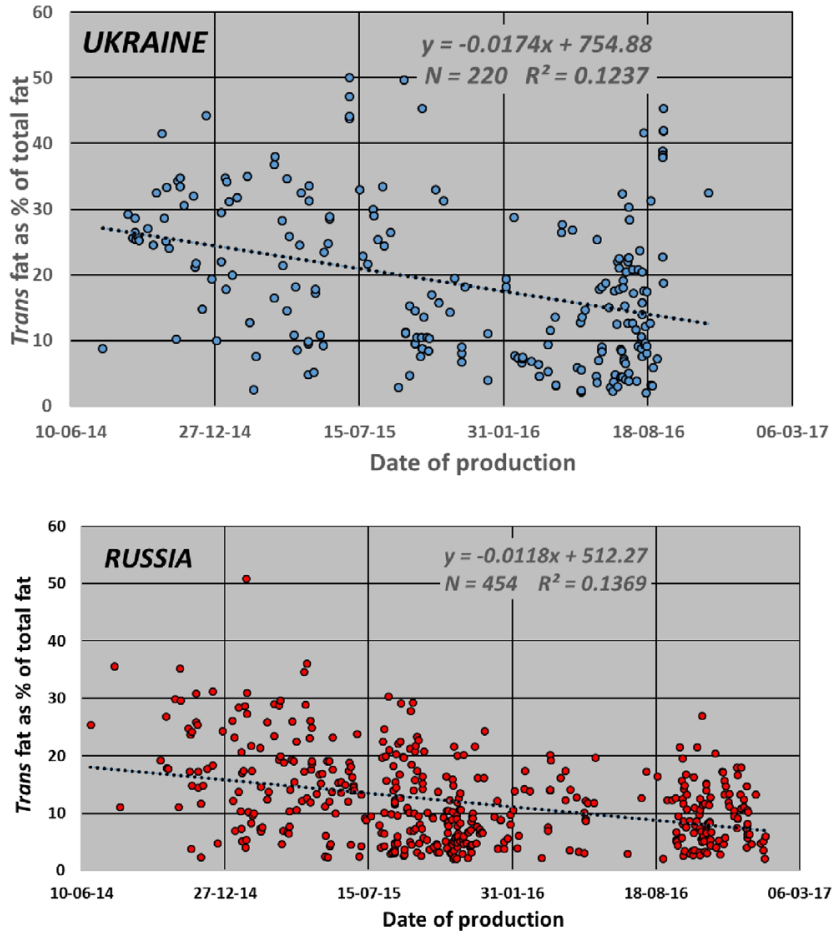

Figure 4 Date of production and industrially produced trans fat (I-TF) as a percentage of total fat for prepackaged biscuits/cakes/wafers that were produced in Russia or Ukraine and obtained in the countries of the former Soviet Union between January 2015 and January 2017. Products obtained in Samarkand, St. Petersburg and Kiev-2 were included if the products had their own trans fat analysis. Only products with more than $2 \%$ fat as I-TF were included.

had more than $6 \mathrm{~g}$ per $100 \mathrm{~g}$ (figure 3). The same was seen for the average concentration of I-TF in fat in products that were obtained in Russia, which had a mean value and SD of 10 (6)\%, compared with considerably higher values in Russian products that were obtained in the other countries (table 1). The same pattern was observed for products that were bought in Ukraine and compared with products that were produced in Ukraine but bought in some of the other countries (table 1). The products that were obtained in Russia were bought more than a year later than the products that were produced in Russia but obtained in the other countries. This same trend was also the case for the products that were obtained in Ukraine and outside of Ukraine. Some of the difference may be due to a decrease in the use of I-TF during the time period (figure 4).

I-TF has also been used in foods such as biscuits/cakes/ wafers because it apparently prolongs the shelf life of the foods. This fact is presently not supported by the findings of this study because 186 products that were produced in Russia with a shelf life of 6 months had TF concentrations of 11 (7)\% mean value (SD) and 37 products with a shelf life of 12 months also had TF concentrations of 11 (7) \%. The corresponding values for products that were produced in Ukraine were for 86 products with a shelf life 
of 6 months, 20 (9)\% and for 30 products with a shelf life of 12 months, $10(6) \%$.

Based on the plasma concentrations of TF in nationally representative groups in 2010 in the USA (3 years after the introduction of mandatory labelling of TF on prepackaged foods and despite a nearly $50 \%$ lower average TF concentration in plasma), there is still a subgroup with very high $\mathrm{TF}$ concentrations, reflecting a subgroup in the general population with a high consumption of $\mathrm{TF}^{4} \mathrm{~A}$ vicious cycle apparently occurs: as long as foods with high amounts of I-TF are present in shops, some consumers will buy them, and as long as they are bought, the foods will be available. This cycle may also occur in the countries of the former Soviet Union. Despite a decline in the average intake of I-TF in many countries in Western Europe ${ }^{16}$ in 2015 , WHO estimated that millions of Europeans still consume TF at levels that significantly increase their risk of CHD. ${ }^{23}$ The findings reported in the present investigation confirm this estimate.

\section{Strength and weaknesses of the study}

The strengths of this study include that the same procedure was used to obtain popular foods in large supermarkets in all 15 countries of the former Soviet Union and in two different regions in the three largest countries and that the samples were analysed for TF in the same laboratory. A limitation of this study is that no other food groups (such as shortenings and margarines) and no unpackaged foods (such as baked goods, sweet rolls, pastries, buns and even unpackaged biscuits/cakes/wafers) were investigated. It was also assumed that if the inclusion words are not present in the list of ingredients, the product contained less than $2 \%$ total fat as TF. The presence of high concentrations of I-TF in biscuits/cakes/wafers may be a sign that I-TF is used in other foods as well. Another limitation is that the average daily intake of I-TF was not measured in any subgroups of the populations but instead was inferred from the availability of popular foods with high amounts of I-TF in large supermarkets. The competition for shelf space in supermarkets is usually fierce. If products do not sell, they are rapidly replaced by other products. A relevant subgroup for intake studies would be the consumers who buy prepackaged biscuits/cakes/ wafers.

\section{Legislation and I-TF in foods}

In the USA in 2015, the Food and Drug Administration revoked the previous GRAS (Generally Recognized As Safe) status of partially hydrogenated oils, which was a step that may remove I-TF from food production in the USA before July 2018, and Canada is following suit. ${ }^{24}$ In 2009, Austria and Switzerland introduced a legislative ban similar to the Danish ban from 2004, followed by Iceland in 2011, Hungary and Norway in 2014, and initiated by Latvia, Georgia, Lithuania, Slovenia and other Eastern European countries including Russia between 2016 and 2018. ${ }^{1325-27}$ The samples for the present study were all collected in the various capitals in 2015 or 2016 (online supplementary table A) before any of the legislative restrictions of I-TF in food were fully implemented in these countries. However, some of their food producers were most likely aware of future legislation. The producers may have gradually started to remove I-TF from some of their products in 2015 and 2016. This removal may be the explanation for the relatively few products with TF in Lithuania and in Latvia. This explanation is apparently not valid for Estonia, which only had eight products with more than $2 \%$ fat as TF and has no internationally published plan for a legislation similar to the two other Baltic countries (figure 1 and table 1 ).

The European Union published a report in 2015, which was originally commissioned in 2011, that 'indicates the need to continue and expedite work in this area by collecting more information'. ${ }^{28} 29$ In the WHO-Europe investigation of the various ways to reduce I-TF in foods, it was concluded that establishing a legal limit for the content of I-TF in foods is potentially the only available option that reduces the risks associated with I-TF faced by all consumers and that doing so may contribute to reducing inequalities. Such a policy is unique in its combination of efficacy, cost-effectiveness and a low potential for negative impact. Removing I-TF from the food supply is possibly one of the most straightforward public health interventions for reducing the risk of CHD. ${ }^{23}$ The trend of using fat with lower amounts of I-TF (figure 4) over time will probably accelerate in 2018 among food factories in Russia due to the Russian legislation ${ }^{27}$ and among factories in Ukraine due to competition with Russian factories. The intake of I-TF in the two largest countries may decrease, along with the intake of I-TF among millions of inhabitants in the adjacent countries due to the large export of biscuits/cakes/wafers from Russia and Ukraine to these countries ${ }^{18}$ (table 1 ).

\section{Future research and implications for policy-makers}

It is of considerable interest whether coronary mortality and admission rates for CHD and stroke will change in countries that have recently introduced legislation that restricts the use of I-TF or intend to do so in the near future in the same way these rates changed in Denmark and in certain counties in New York. ${ }^{7-9}$

On the basis of data from 2009 to 2011, there is a fivefold difference in age-standardised mortality rates of CHD between some countries in Western Europe and countries in Central and Eastern Europe, with Central Asia having the highest rates. ${ }^{10}$ Central Eastern Europe and Central Asia are the regions in the world with the highest current age-standardised cardiovascular mortality rates, which are more than twice those of Latin America and the Caribbean. ${ }^{30}$ These differences cannot be explained only by differences in the intake of I-TF between the countries. The present study demonstrates that there is a presence of I-TF in popular foods in the countries of the former Soviet Union, which have excessively high CHD mortality rates. The restriction of the use of I-TF in foods, either voluntarily by food producers or more efficiently by legislation, may be an easily 
implemented primary strategy for some reduction of cardiovascular diseases in these countries.

Acknowledgements The authors acknowledge the support from Jenny Vissings Foundation, University of Copenhagen and the Department of Clinical Biochemistry, Copenhagen University Hospital, Gentofte, Denmark.

Contributors SS was responsible for the concept design of the study, for collection of food items, registration and labelling, and writing the manuscript. SS is the manuscript guarantor.

Funding This work was supported by Jenny Vissings Foundation, University of Copenhagen and Department of Clinical Biochemistry, Copenhagen University Hospital, Gentofte, Denmark.

Competing interests None declared.

Patient consent for publication Not required.

Provenance and peer review Not commissioned; externally peer reviewed.

Data sharing statement The data used to construct figures $1-4$, tables 1 and 2 , and online supplementary tables A and B can be shared by emailing SS.

Open access This is an open access article distributed in accordance with the Creative Commons Attribution Non Commercial (CC BY-NC 4.0) license, which permits others to distribute, remix, adapt, build upon this work non-commercially, and license their derivative works on different terms, provided the original work is properly cited, appropriate credit is given, any changes made indicated, and the use is non-commercial. See: http://creativecommons.org/licenses/by-nc/4.0/.

\section{REFERENCES}

1. Gebauer SK, Destaillats F, Dionisi F, et al. Vaccenic acid and trans fatty acid isomers from partially hydrogenated oil both adversely affect LDL cholesterol: a double-blind, randomized controlled trial. Am J Clin Nutr 2015;102:1339-46.

2. de Souza RJ, Mente A, Maroleanu A, et al. Intake of saturated and trans unsaturated fatty acids and risk of all cause mortality, cardiovascular disease, and type 2 diabetes: systematic review and meta-analysis of observational studies. BMJ 2015;351:h3978.

3. Li H, Zhang Q, Song J, et al. Plasma trans-fatty acids levels and mortality: a cohort study based on 1999-2000 National Health and Nutrition Examination Survey (NHANES). Lipids Health Dis 2017;16:176

4. Yang $Q$, Zhang Z, Loustalot F, et al. Plasma trans-fatty acid concentrations continue to be associated with serum lipid and lipoprotein concentrations among us adults after reductions in transfatty acid intake. J Nutr 2017;147:896-907.

5. Hirata Y, Takahashi M, Kudoh Y, et al. trans -Fatty acids promote proinflammatory signaling and cell death by stimulating the apoptosis signal-regulating kinase 1 (ASK1)-p38 pathway. J Biol Chem 2017:292:8174-85.

6. Brouwer IA, Wanders AJ, Katan MB. Trans fatty acids and cardiovascular health: research completed? Eur J Clin Nutr 2013;67:541-7.

7. Restrepo BJ, Rieger M. Denmark's policy on artificial trans fat and cardiovascular disease. Am J Prev Med 2016;50:69-76.

8. Restrepo BJ, Rieger M. Trans fat and cardiovascular disease mortality: evidence from bans in restaurants in New York. $J$ Health Econ 2016:45:176-96.

9. Brandt EJ, Myerson R, Perraillon MC, et al. Hospital admissions for myocardial infarction and stroke before and after the trans-fatty acid restrictions in New York. JAMA Cardiol 2017;2:627-34.
10. Nichols M, Townsend N, Scarborough P, et al. Cardiovascular disease in Europe 2014: epidemiological update. Eur Heart $J$ 2014;35:2950-9.

11. Micha R, Khatibzadeh S, Shi P, et al. Global, regional, and national consumption levels of dietary fats and oils in 1990 and 2010: a systematic analysis including 266 country-specific nutrition surveys. BMJ 2014;348:g2272.

12. Perova NV, Metel'skaia VA, Boĭtsov SA. [Trans isomers of unsaturated fatty acids increase the risk of atherosclerosis-related circulatory system diseases]. Ter Arkh 2013;85:113-7.

13. Boytsov SA, Perova NV. To lower trans fatty acid intake as an important condition for the reduction of cardiovascular mortality. Profilakticheskaya meditsina 2017;20:4-9.

14. Meremäe K, Roasto M, Kuusik S, et al. Trans fatty acid contents in selected dietary fats in the Estonian market. $J$ Food Sci 2012;77:T163-T168.

15. FEEDcities project. The food environment description in cities in Eastern Europe and Central Asia - Tajikistan and Kyrgyzstan. Technical report, WHO Europe, June 2017 and August 2017. http:// www.euro.who.int/_data/assets/pdf_file/0012/353001/FEED-TJKreport.pdf?ua=1. http://www.euro.who.int/_data/assets/pdf_file/ 0006/351996/FEED-KGZ-report-web-new.pdf?ua=1 (accessed Nov 2018).

16. Wanders AJ, Zock PL, Brouwer IA. Trans fat intake and its dietary sources in general populations worldwide: a systematic review. Nutrients 2017:9:840.

17. Stender S, Astrup A, Dyerberg J. A trans European Union difference in the decline in trans fatty acids in popular foods: a market basket investigation. BMJ Open 2012;2:e000859.

18. Post-Soviet states. https://en.wikipedia.org/wiki/Post-Soviet_states\# General statistics (accessed Nov 2018).

19. Kravic S, Suturovic Z, Svarc-Gajic J, et al. Fatty acid composition including trans isomers of Serbian biscuits. Hem Ind 2011;65:139-46.

20. Stender S, Astrup A, Dyerberg J. Tracing artificial trans fat in popular foods in Europe: a market basket investigation. BMJ Open 2014;4:e005218.

21. Stender S, Astrup A, Dyerberg J. Artificial trans fat in popular foods in 2012 and in 2014: a market basket investigation in six European countries. BMJ Open 2016;6:e010673.

22. International Article Number (EAN). https://da.wikipedia.org/wiki/ International_Article_Number_(EAN) (accessed Nov 2018).

23. WHO. Eliminating trans fats in Europe-a policy brief (2015). http:// www.euro.who.int/en/health-topics/disease-prevention/nutrition/ publications/2015/eliminating-trans-fats-in-europe-a-policy-brief2015 (accessed Nov 2018).

24. FDA Cuts Trans Fat in Processed Foods. U.S. trans fat ban goes into effect. https://experiencelife.com/article/u-s-trans-fat-ban-goes-intoeffect/ (accessed Nov 2018).

25. Vučić V, Arsić A, Petrović S, et al. Trans fatty acid content in Serbian margarines: urgent need for legislative changes and consumer information. Food Chem 2015;185:437-40.

26. Wilczek MM, Olszewski R, Krupienicz A. Trans-fatty acids and cardiovascular disease: urgent need for legislation. Cardiology 2017;138:254-8.

27. Trans fat legislation in republic of Russia. http://rospotrebnadzor.ru/ about/info/news/news_details.php?ELEMENT_ID=9510\&sphrase_id= 1487827 (accessed Nov 2018).

28. Report from the Commission. European Commission DG health and food safety. http://ec.europa.eu/dgs/health_food-safety/dyna/enews/ enews.cfm?al_id=1650 (accessed Nov 2018).

29. Open public consultation on the initiative to limit industrial trans fats intakes in the EU. https://ec.europa.eu/info/consultations/openpublic-consultation-initiative-limit-industrial-trans-fats-intakes-eu_en (accessed Nov 2018).

30. Barquera S, Pedroza-Tobías A, Medina C, et al. Global overview of the epidemiology of atherosclerotic cardiovascular disease. Arch Med Res 2015;46:328-38. 